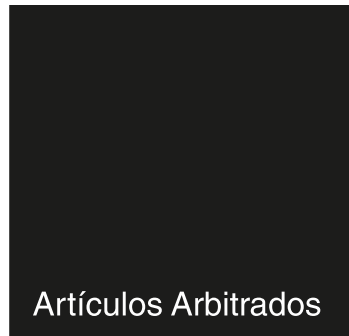

\title{
Estimación del índice de vegetación en entornos urbanos forestados consolidados de baja densidad del área Metropolitana de Mendoza, Argentina
}

Mariela Edith Arboit

Doctora en Arquitectura. Investigadora adjunta del CONICET. Instituto de Ciencias Humanas, Sociales y Ambientales. (INCIHUSA-CONICET).

marboit@mendoza-conicet.gob.ar

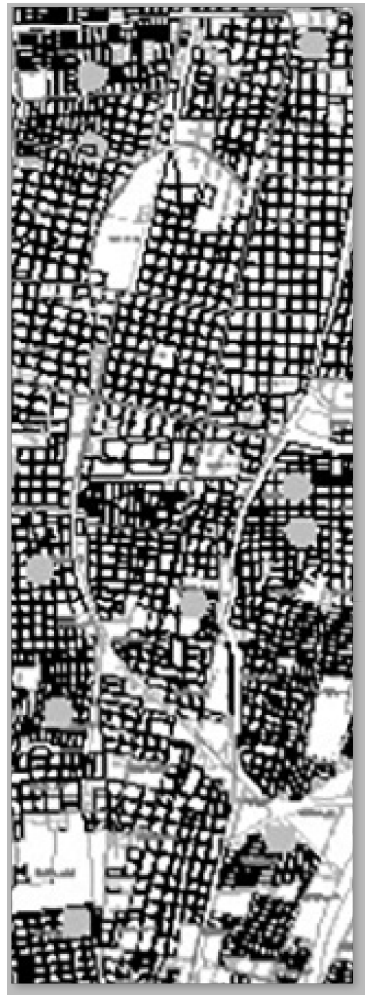




\section{Resumen}

El objetivo del trabajo es estudiar la cobertura vegetal en entornos urbanos de baja densidad del Área Metropolitana de Mendoza (AMM), Argentina, a fin de comprender la morfología de ciudad forestada en clima árido. A nivel de verde urbano se ha determinado el índice de vegetación de diferencia normalizada (NDVI) a partir de datos satelitales para 32 manzanas urbanas representativas en el AMM y se cuantificó el mismo indicador en el AMM. El valor medio obtenido para los 32 entornos analizados es de 0.206 , con el índice de vegetación más alto de 0.290 relacionado con el efecto positivo de la cubierta forestal y un valor mínimo de 0.148 en entornos con bajo porcentaje de arbolado urbano, alto porcentaje de transmisividad a la radiación solar y gran cantidad de superficie mineralizada expuesta directamente a dicha radiación. Se han podido conocer las condiciones actuales y la formulación de un diagnóstico de cobertura vegetal sobre la base del índice de vegetación.

\section{Palabras clave}

Desarrollo urbano sostenible; índice de vegetación; entornos urbanos forestados; morfología urbano-edilicia, energía.

\section{Abstract}

Estimating forest cover in established low density urban areas in the Metropolitan area of Mendoza, Argentina. The object of this study is to estimate forest cover in the low density urban environment of the Mendoza Metropolitan Area (MMA) in Argentina, in order to understand the morphology of a forested city in an arid climate.

On the urban green space level, the Normalized Difference Vegetation Index (NDVI) has been quantified from satellite data, for 32 representative city blocks in the MMA.

The results obtained indicate mean values for the 32 environments analyzed of 0.206 , with the highest indices of 0.290 through the positive effect of vegetation cover, and, on the other hand, with minimum indices of 0.148 in environments with a low percentage of trees and a large area of mineralized surface directly exposed to solar radiation.

As a result of such a process, it is possible to determine current conditions and the formulation of a vegetation coverage diagnosis based on Normalized Difference Vegetation Index.

\section{Keywords}

Sustainable urban development; vegetation index; forested urban environments; urban-building morphology; energy. 
Estimación del índice de vegetación en entornos urbanos forestados consolidados de baja densidad del área Metropolitana de Mendoza, Argentina

\section{Introducción}

El constante crecimiento que va incrementando en forma exponencial la población mundial (MEADows, D. 1992), el consumo de los recursos no renovables, la contaminación, la tasa de urbanización en países en desarrollo (ICES, 2013) se tornan particularmente críticos en los ámbitos urbanos y requieren el estudio de la morfología urbana actual y previsible en el futuro, que permita establecer pautas de evolución sin obstaculizar el uso pleno de los recursos naturales: radiación solar, iluminación natural y ventilación natural.

El crecimiento urbano lleva a un consumo intensivo de recursos naturales no renovables y genera ingentes cantidades de contaminantes que no son posibles de procesar, absorber y neutralizar. Las áreas interrelacionadas del hábitat y la energía ocupan una posición central en la problemática del ambiente global. Actuando sobre ellas pueden obtenerse beneficios significativos en plazos relativamente breves, al menos en cuanto a la reducción de los deterioros en avance. El desarrollo del potencial de eficiencia energética en el ámbito urbano-edilicio requiere la implementación de políticas de control de la morfología que respondan a los objetivos específicos de planificación urbana y energética en sus correspondientes niveles de intervención. En el campo científico, mucho se ha discutido acerca de la interrelación entre consumo de energía y morfología urbana (OwENs, 1986; Givoni, 1998; BREHENY, 1996; Mascaró, 1996).

El balance de energía a nivel urbano fue definido (ОкE, 1988), pero la ecuación es compleja por la diversidad de superficies urbanas y la variación de indicadores en cada punto dentro de la ciudad, por lo que requiere simplificaciones, en tanto la energía disponible para calentar el aire, el suelo o evaporar el agua es dependiente del balance de radiación (OKE, 19711991; Roth, M. 2013; HaRman, 2003; Haider, 1997). La mayoría de las ciudades son fuentes generadoras de calor condicionadas por factores meteorológicos (irradiancia solar, nubosidad, velocidad del viento, humedad) y por la estructura de las variables urbano-edilicias (impermeabilización superficial, propiedades térmicas de los materiales, geometría de la superficie, arbolado y superficies vegetadas). Algunas causas que intervienen en el incremento de la temperatura son: aumento de calor antropogénico, reducción de la evapotranspiración, aumento de almacenamiento de calor, aumento de la radiación neta y reducción de la convección. En este sentido, cubierta forestal y las áreas verdes juegan un importante rol en el mejoramiento de la calidad del ambiente urbano y proveen grandes beneficios 
sociales y ambientales que favorecen la calidad de vida en las ciudades. La contribución del arbolado urbano en la mejora del microclima, la calidad del aire y de vida está muy bien documentada (Bernatzky, 1982; Rowntree, 1986; McPerson, 1992; Dessì, 2002 ; SANTAMouris, 2000), con beneficios como la reducción la isla de calor (AKBARI Y KoNOPACKI, 2005), la disminución de $\mathrm{CO}_{2}, \mathrm{NO}_{2}, \mathrm{O}_{3}$, la absorción de contaminantes y la reducción de la polución del aire (McPERSON y Simpson, 1998; NoWAK ET ÁL., 2002; Scudo, 2003).

Las temáticas referidas a los beneficios regionales de los árboles y la reducción de la isla de calor urbano registran en los últimos años un aumento exponencial de investigaciones y trabajos alcanzados (AKBARI, 2002; Block ET ÁL., 2012; Simpson, 2002; TookE ET ÁL., 2011, ARMSON ET ÁL., 2012; Hamada y Ohta, 2010; Loughner, 2012; Shashua-Bar y Hoffman, 2000; Shashua-Bar et Ál., 2011 y 2009; PARKER, 1983; PAPADAKIS ET ÁL., 2001). Los beneficios de refrigeración del arbolado en la estación cálida están determinados por dos factores principales: 1) la reducción del acceso a la radiación solar de las superficies por debajo de la copa del arbolado, que permite una disminución de las cargas térmicas de los edificios y la habitabilidad de los espacios públicos abiertos (Gómez Munoz et ÁL., 2010; Heisler, 1986, Cantón, 2003, Ling TANG et ÁL., 2013, Аввогт, 2013) у 2) la evapotranspiración, usando un porcentaje de la radiación que interceptan para evaporar el agua de sus hojas (Monteith And Unsworth, 1990).

En cuanto a aspectos metodológicos considerados, son importantes los trabajos sobre la determinación del índice de vegetación de diferencia normalizada (NDVI), que proporciona la fracción de la radiación fotosintéticamente activa interceptada por la vegetación (MoNTEITH, 1973; LENNEY ET ÁL., 1996), el funcionamiento en el ecosistema (VIrginia y WaLL, 2001), la identificación de ecorregiones (RAMSEY ET ÁL., 1995) y el seguimiento de patrones fenológicos con los cambios estacionales y de crecimiento (HuEte y Liu, 1994). El trabajo evalúa la cobertura vegetal en manzanas urbanas de baja densidad del Área Metropolitana de Mendoza (AMM) y compara diversas estructuras urbanas y territoriales sobre la base del índice de vegetación de diferencia normalizada (NDVI).

\section{Aspectos regionales}

En el contexto de la región árida del centro-oeste argentino, el Área Metropolitana de Mendoza (AMM) presenta evidentes signos de deterioro ambiental. Entre las causas más 
Estimación del índice de vegetación en entornos urbanos forestados consolidados de baja densidad del área Metropolitana de Mendoza, Argentina

significativas de este deterioro se mencionan la morfología urbano-edilicia, la tecnología implementada para la habitabilidad higrotérmica; el creciente deterioro de la infraestructura y el arbolado urbano, la progresiva precarización del hábitat de los sectores carenciados, la emisión de gases de invernadero y particulados; la presión del microclima urbano y el mal uso del recurso hídrico, la expansión de la mancha urbana sobre el piedemonte (hacia el oeste) y sobre las tierras agrícolas de mayor fertilidad del oasis (hacia el este), lo que contribuye a la desertificación del oasis periurbano y agrava los riesgos sísmicos y aluvionales en las zonas adyacentes a la zona construida.

La ciudad se organizó históricamente a partir de los sistemas calle, acequia y árbol. En este modelo de ciudad forestada, la presencia del arbolado posibilitó beneficios ambientales y energéticos en ambas estaciones extremas. La preservación del modelo de ciudad forestada está relacionada con la disponibilidad hídrica, el sellamiento de suelos en los espacios públicos y privados. Otro aspecto que considerar es la modificación del clima urbano. Es producida esencialmente por las diferentes características térmicas de los materiales constructivos de las ciudades. La sustitución de espacios verdes por grandes masas construidas, calles y avenidas es mayor a medida que disminuye la distancia al centro de la ciudad. La preservación y mejora de la ciudad forestada, patrimonio cultural de Mendoza, requerirá a los organismos de investigación, los entes de gestión y la ciudadanía en general un trabajo conjunto interdisciplinario y consensuado hacia el futuro.

En la región los recursos climáticos disponibles son abundantes para posibilitar la implementación de diseños y tecnologías para la eficiencia energética disponibles y técnicamente viables, aun sin mediar el desarrollo e incorporación de nuevas tecnologías constructivas o energéticas. Los recursos potencialmente más importantes son: la radiación solar 4.58 $\mathrm{Kwh} / \mathrm{m}^{2}$ día a $5.55 \mathrm{Kwh} / \mathrm{m}^{2}$ (calefacción de espacios, calentamiento de agua y generación fotovoltaica in situ), la amplitud térmica día-noche asociada con la brisa estival nocturna (enfriamiento convectivo nocturno), las bajas temperaturas aparentes de cielo (enfriamiento radiativo nocturno), los bajos valores de humedad atmosférica (enfriamiento evaporativo) y la alta luminancia del cielo diurno (iluminación natural de espacios). Cada una de estas estrategias, asociadas con mayores niveles de conservación de energía en las envolventes edilicias, puede aportar mediante su implementación masiva ahorros de energía convencional y sustanciales mejoras en la calidad de vida de la población, especialmente en medios urbanos. Sin embargo, aun cuando la viabilidad técnica de estas estrategias esté 
Cuadro 1. Datos regionales. Sitio y clima

Coordenadas geográficas: latitud -32.85, longitud -63.85 y altitud 750. Datos climáticos: i. horas anuales: en confort $21,5 \%$, calefacción necesaria 70,00 \%, enfriamiento necesario 8,5 \%, ii. grados-día anuales: calefacción (Base $18^{\circ} \mathrm{C}$ ) 1384, enfriamiento (Base $23^{\circ} \mathrm{C}$ ) 163, III. Radiación solar global media anual: 18,06 $\mathrm{MJ} / \mathrm{m}^{2}$ día, predominio de cielos claros. Heliofonía Relativa 63 \%. Índice de Claridad 0.59. Media anual de precipitaciones $200 \mathrm{~mm}$. Humedad Relativa $56 \%$. Velocidad del viento entre 7 y $23 \mathrm{Km} / \mathrm{h}$ con dirección sur y sureste. Población: 937145 habitantes (censo nacional 2010). Superficie de análisis del Área Metropolitana de Mendoza (AMM), Argentina: $252 \mathrm{~km}^{2}$

Figura 1. Ubicación de las Unidades de Integración Territorial (UIT). Provincia de Mendoza: 1) oasis; 2) planicies; 3) montañas; 4) unidades varias; 5) piedemontes y UIT menores. Fuente: Agencia Provincial de Ordenamiento Territorial. SIAT (APOT), LADYOT (CCT-CONICET), Instituto CIFOT (FFYL, UNCuyo) http://www. siat.mendoza.gov.ar; en superposición con área de la imagen satelital

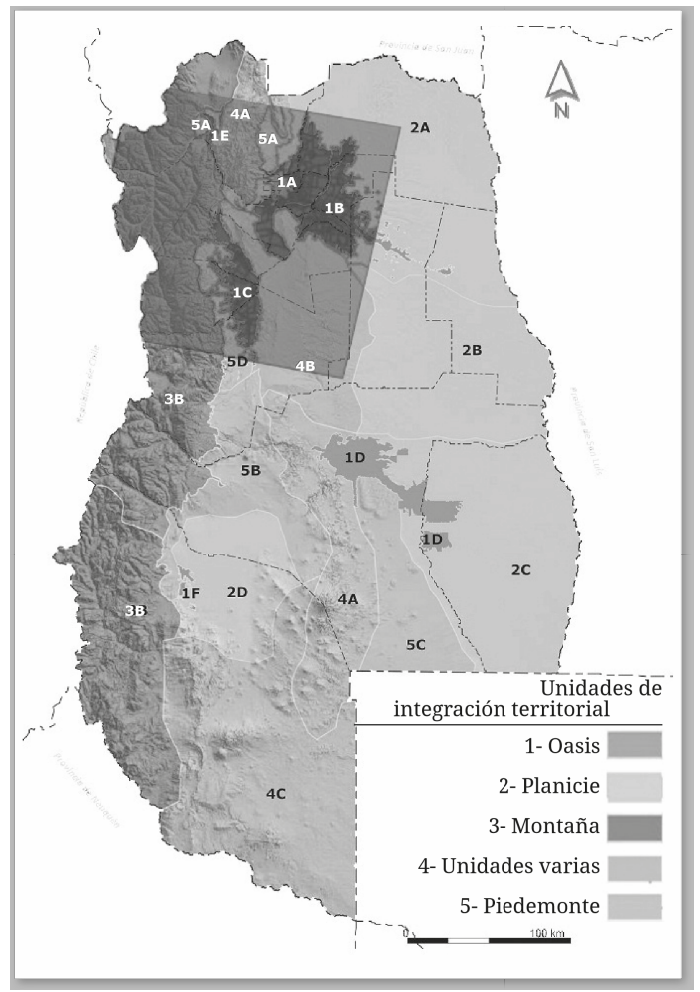

localmente demostrada (DE RosA, 1988), las estrategias energético-ambientales no han sido exhaustivamente estudiadas y constituyen un área de vacancia que posibilitaría una transición progresiva hacia la sostenibilidad energética y ambiental del parque edilicio regional.

Para evitar el deterioro creciente de la ciudad forestada, se deben identificar y evaluar las estrategias de manejo de un ambiente urbano sostenible en sí mismo y en sus vínculos con la región. Siendo Mendoza una zona de alta vulnerabilidad a cambios tales como la desertificación, el calentamiento global, la contaminación del aire, es primordial proyectar su influencia para prever cómo será la incidencia de estos sobre la zona. 


\section{Trabajo previo}

Las etapas ya concluidas han sido las siguientes:

1) Recopilación de la información catastral disponible y mapeo de esta para toda el AMM, zonificación de áreas de baja densidad que considerar en el estudio.

2) Definición de un conjunto de variables morfológicas, urbano-edilicias. Se toma a la manzana urbana como unidad de análisis. Variables urbanas: forma de las manzanas, orientación de las manzanas, ancho de los canales viales, características de la arboleda urbana (magnitud, transmisividad y plenitud). Variables edilicias: morfología edilicia, factor de forma (FF), factor de ocupación del suelo (FOS), factor de ocupación total (FOT). 3) Selección de una muestra representativa de manzanas urbanas para su análisis detallado. Se determinó un conjunto preliminar de 32 unidades para cada una de las tres variables consideradas como primarias -forma de las manzanas, orientación de las manzanas y morfología edilicia-, a partir de su lectura sobre antecedentes. Se establece la representatividad porcentual de los distintos tipos de cada variable y, según esta, se procede a completar un conjunto de 32 unidades. La distribución espacial se realiza mediante un método aleatorio (random) (figura 2). Se completa el procedimiento relevando las manzanas seleccionadas.

4) Relevamiento in situ del arbolado urbano.

5) Relevamiento in situ de las restantes variables urbano-edilicias (tabla 1) (ARBoIt ET AL., 2008 y 2010).

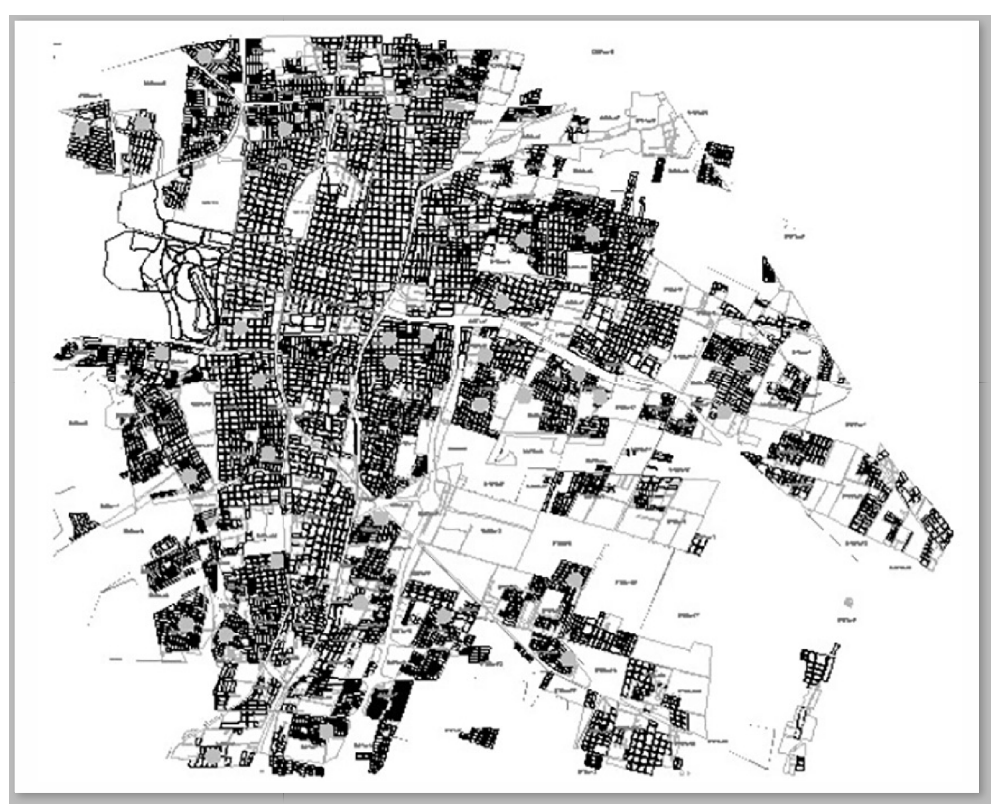




\section{A continuación se presentan los 32 escenarios analizados}

Tabla I

\section{Listado de valores de las variables urbanas y edilicias del conjunto muestral}

\begin{tabular}{|c|c|c|c|c|c|c|c|c|c|c|}
\hline \multicolumn{3}{|c|}{ Escenario } & \multicolumn{5}{|c|}{$\begin{array}{c}\text { Variables } \\
\text { urbanas }\end{array}$} & \multicolumn{3}{|c|}{$\begin{array}{l}\text { Variables } \\
\text { edilicias }\end{array}$} \\
\hline \multirow[b]{2}{*}{ N. ${ }^{\circ}$} & \multicolumn{2}{|c|}{ Manzanas } & \multirow[b]{2}{*}{ 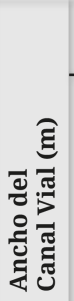 } & \multicolumn{3}{|c|}{$\begin{array}{c}\text { Arbolado } \\
\text { urbano }\end{array}$} & \multirow[b]{2}{*}{ 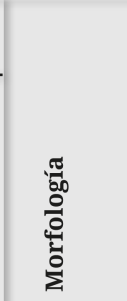 } & \multirow[b]{2}{*}{ 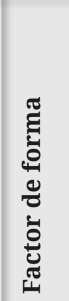 } & \multirow[b]{2}{*}{ 足 } & \multirow[b]{2}{*}{ 可 } \\
\hline & 苞 & 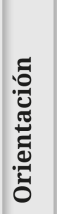 & & 范 & 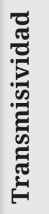 & 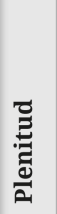 & & & & \\
\hline 1 & 05:02 & -5 & 20 & $2^{a}$ & 52 & 57 & Irregular & 0.49 & 0.74 & 0.97 \\
\hline 2 & 05:03 & -6 & 20 & $2^{a}$ & 52 & 55 & Irregular & 0.64 & 0.56 & 0.78 \\
\hline 3 & 05:02 & -6 & 20 & $2^{\mathrm{a}}$ & 52 & 65 & Irregular & 0.60 & 0.72 & 0.98 \\
\hline 4 & 05: 03 & 87 & 20 & $2^{\mathrm{a}}$ & 43 & 69 & Irregular & 0.61 & 0.69 & 0.91 \\
\hline 5 & 05:03 & 86 & 20 & $2^{\mathrm{a}}$ & 52 & 70 & Irregular & 0.59 & 0.74 & 1.00 \\
\hline 6 & 05:04 & -6 & 20 & $1^{\mathrm{a}}$ & 35 & 77 & Irregular & 0.68 & 0.60 & 0.66 \\
\hline 7 & 05:05 & -5 & 20 & $1^{a}$ & 43 & 71 & Irregular & 0.63 & 0.68 & 0.75 \\
\hline 8 & 05:05 & -1 & 20 & $1^{\mathrm{a}}$ & 51 & 81 & Irregular & 0.89 & 0.57 & 0.61 \\
\hline 9 & 05:04 & -1 & 20 & $1^{\mathrm{a}}$ & 51 & 79 & Irregular & 0.64 & 0.58 & 0.61 \\
\hline 10 & 05:04 & 74 & 20 & $1^{\mathrm{a}}$ & 43 & 76 & Irregular & 0.65 & 0.62 & 0.62 \\
\hline 11 & 05:04 & 74 & 20 & $1^{\mathrm{a}}$ & 43 & 68 & Irregular & 0.88 & 0.52 & 0.52 \\
\hline 12 & 05:04 & 74 & 16 & $1^{\mathrm{a}}$ & 43 & 69 & Irregular & 0.57 & 0.67 & 0.67 \\
\hline 13 & 05:02 & -23 & 13 & $2^{\mathrm{a}}$ & 43 & 64 & Regular & 0.62 & 0.55 & 0.57 \\
\hline 14 & 05:02 & -23 & 13 & $2^{a}$ & 43 & 74 & Regular & 0.63 & 0.55 & 0.56 \\
\hline 15 & 05:02 & -23 & 13 & $2^{\mathrm{a}}$ & 43 & 85 & Regular & 0.64 & 0.51 & 0.52 \\
\hline 16 & 05:02 & -23 & 13 & $2^{a}$ & 43 & 76 & Regular & 0.59 & 0.53 & 0.54 \\
\hline
\end{tabular}

* transmisividad estación de invierno

\begin{tabular}{|c|c|c|c|c|c|c|c|c|c|c|}
\hline \multicolumn{3}{|c|}{ Escenario } & \multicolumn{5}{|c|}{$\begin{array}{l}\text { Variables } \\
\text { urbanas }\end{array}$} & \multicolumn{3}{|c|}{$\begin{array}{l}\text { Variables } \\
\text { edilicias }\end{array}$} \\
\hline \multirow[b]{2}{*}{ N. ${ }^{\circ}$} & \multicolumn{2}{|c|}{ Manzanas } & \multirow[b]{2}{*}{ 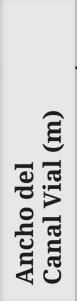 } & \multicolumn{3}{|c|}{$\begin{array}{c}\text { Arbolado } \\
\text { urbano }\end{array}$} & \multirow[b]{2}{*}{ 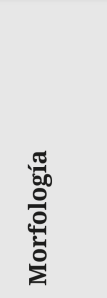 } & \multirow[b]{2}{*}{ 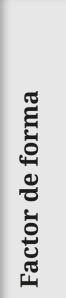 } & \multirow[b]{2}{*}{ 号 } & \multirow[b]{2}{*}{ 㝏 } \\
\hline & 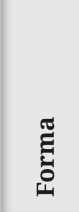 & & & 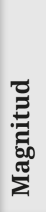 & 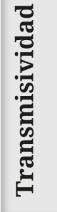 & 胥 & & & & \\
\hline 17 & 05:02 & -23 & 13 & $2^{a}$ & 43 & 83 & Regular & 0.53 & 0.53 & 0.80 \\
\hline 18 & 05:02 & -23 & 13 & $2^{\mathrm{a}}$ & 43 & 67 & Regular & 0.54 & 0.52 & 0.79 \\
\hline 19 & 05:01 & 65 & 15 & $3^{a}$ & 43 & 54 & Regular & 0.68 & 0.52 & 0.55 \\
\hline 20 & 05:01 & 65 & 15 & $3^{\mathrm{a}}$ & 43 & 57 & Regular & 0.56 & 0.61 & 0.61 \\
\hline 21 & 05:01 & 65 & 15 & $3^{\mathrm{a}}$ & 43 & 54 & Regular & 0.62 & 0.57 & 0.59 \\
\hline 22 & 05:02 & 65 & 15 & $3^{\mathrm{a}}$ & 39 & 47 & Regular & 0.62 & 0.58 & 0.58 \\
\hline 23 & 05:02 & 65 & 15 & $3^{a}$ & 39 & 67 & Regular & 0.64 & 0.55 & 0.56 \\
\hline 24 & 05:02 & 65 & 15 & $3^{a}$ & 39 & 56 & Regular & 0.7 & 0.52 & 0.53 \\
\hline 25 & 05:02 & -24 & 15 & $2^{\mathrm{a}}$ & 43 & 66 & Regular & 0.63 & 0.60 & 0.60 \\
\hline 26 & 05:02 & -24 & 15 & $2^{\mathrm{a}}$ & 43 & 71 & Regular & 0.61 & 0.57 & 0.57 \\
\hline 27 & 05:01 & -24 & 15 & $2^{\mathrm{a}}$ & 43 & 67 & Regular & 0.61 & 0.58 & 0.58 \\
\hline 28 & 05:02 & -24 & 15 & $2^{a}$ & 43 & 57 & Regular & 0.64 & 0.54 & 0.54 \\
\hline 29 & 05:03 & 67 & 18 & $1^{\mathrm{a}}$ & 43 & 79 & Regular & 0.58 & 0.63 & 1.05 \\
\hline 30 & 05:03 & 67 & 18 & $1^{a}$ & 43 & 68 & Regular & 0.56 & 0.65 & 1.08 \\
\hline 31 & 05:03 & 67 & 18 & $1^{a}$ & 43 & 74 & Regular & 0.56 & 0.66 & 1.08 \\
\hline 32 & 05:03 & 67 & 18 & $1^{\mathrm{a}}$ & 43 & 68 & Regular & 0.53 & 0.69 & 1.16 \\
\hline
\end{tabular}


Estimación del índice de vegetación en entornos urbanos forestados consolidados de baja densidad del área Metropolitana de Mendoza, Argentina

\section{Metodología actual}

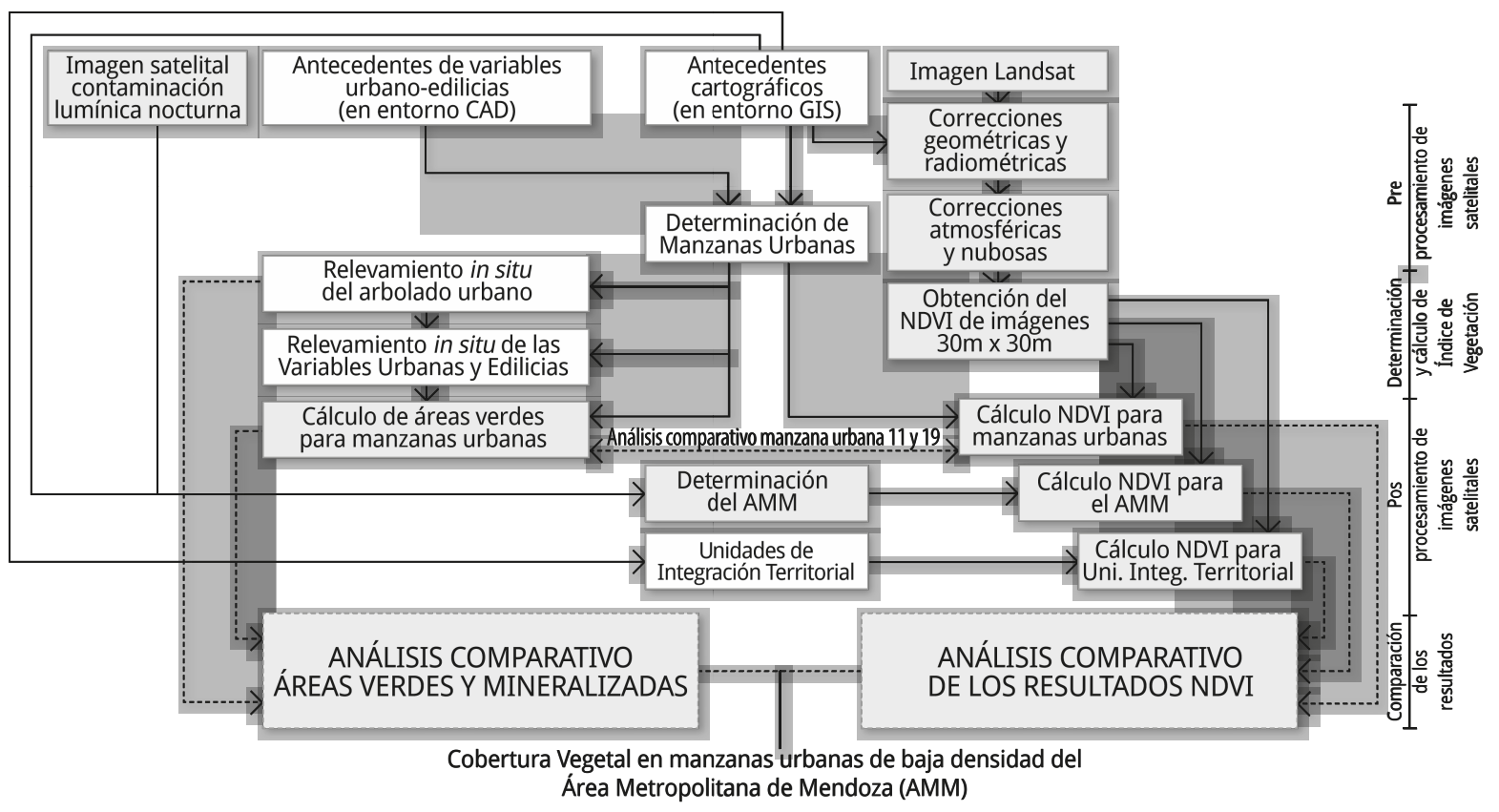

Figura 3. Cuadro metodológico con los pasos seguidos. Fuente: elaboración propia

En una primera etapa se cuantificaron las áreas verdes superficiales (cobertura vegetal del suelo) privadas y públicas; áreas no mineralizadas ni selladas (acequias permeables, terreno desnudo) y superficies mineralizadas (calles, veredas, acequias hormigonadas, edificios, impermeable privada) (figuras 3 y 4). Se realizó un inventario a partir de datos catastrales, antecedentes, fotografías aéreas y relevamiento en metros cuadrados para cada una de las unidades muestrales. Se cuantificaron áreas verdes superficiales y desde una vista aérea, utilizando el modelo i-Tree Canopy, se cuantificó la cubierta forestal (ElLINGsworTH, 2016). 


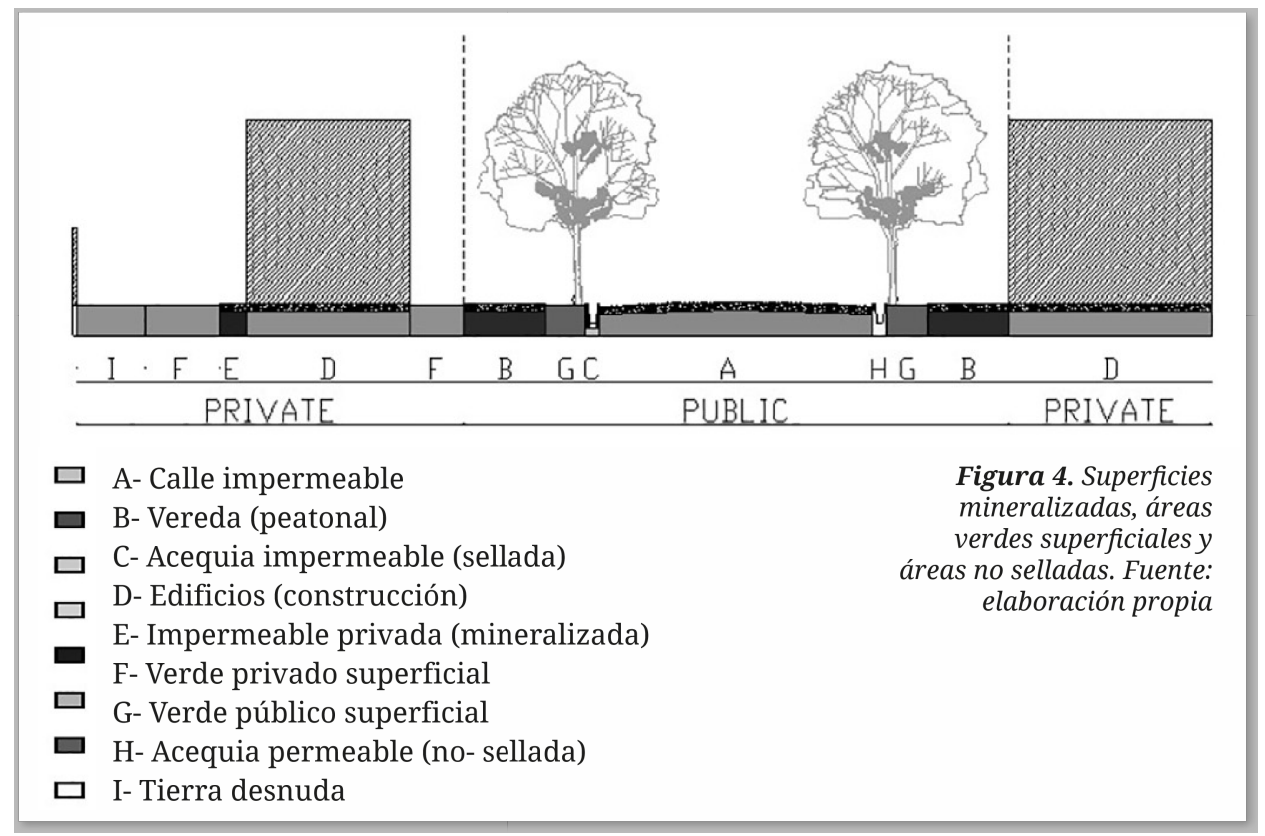

En una segunda etapa se analizaron imágenes satelitales provenientes de Landsat 5 TM (Thematic Mapper- NASA Landsat Enhanced Thematic). Las características técnicas del sensor remoto son: altitud $705 \mathrm{~km}$; inclinación 98.2 ecuador 9:45 AM ( \pm 15 min.); período de revolución 99 minutos 14,5 órbitas/día; repetición de cobertura cada 16 días. Las imágenes están compuestas por siete bandas espectrales con una resolución espacial de 30 metros x 30 metros para las bandas 1 a 5 y 7 . El tamaño de la escena es de $170 \mathrm{~km}$ norte-sur por $183 \mathrm{~km}$ este-oeste y una resolución radiométrica 8 bits (256 niveles de grises).

Metodológicamente se prepararon los antecedentes cartográficos en entorno GIS, se seleccionaron y descargaron de imágenes satelitales para la estación de verano en función de ofrecer una mejor visualización espacial de los tipos de coberturas, en condiciones de cielo claro; posteriormente se realizó la georreferenciación (figuras 3 y 5). 
Estimación del índice de vegetación en entornos urbanos forestados consolidados de baja densidad del área Metropolitana de Mendoza, Argentina

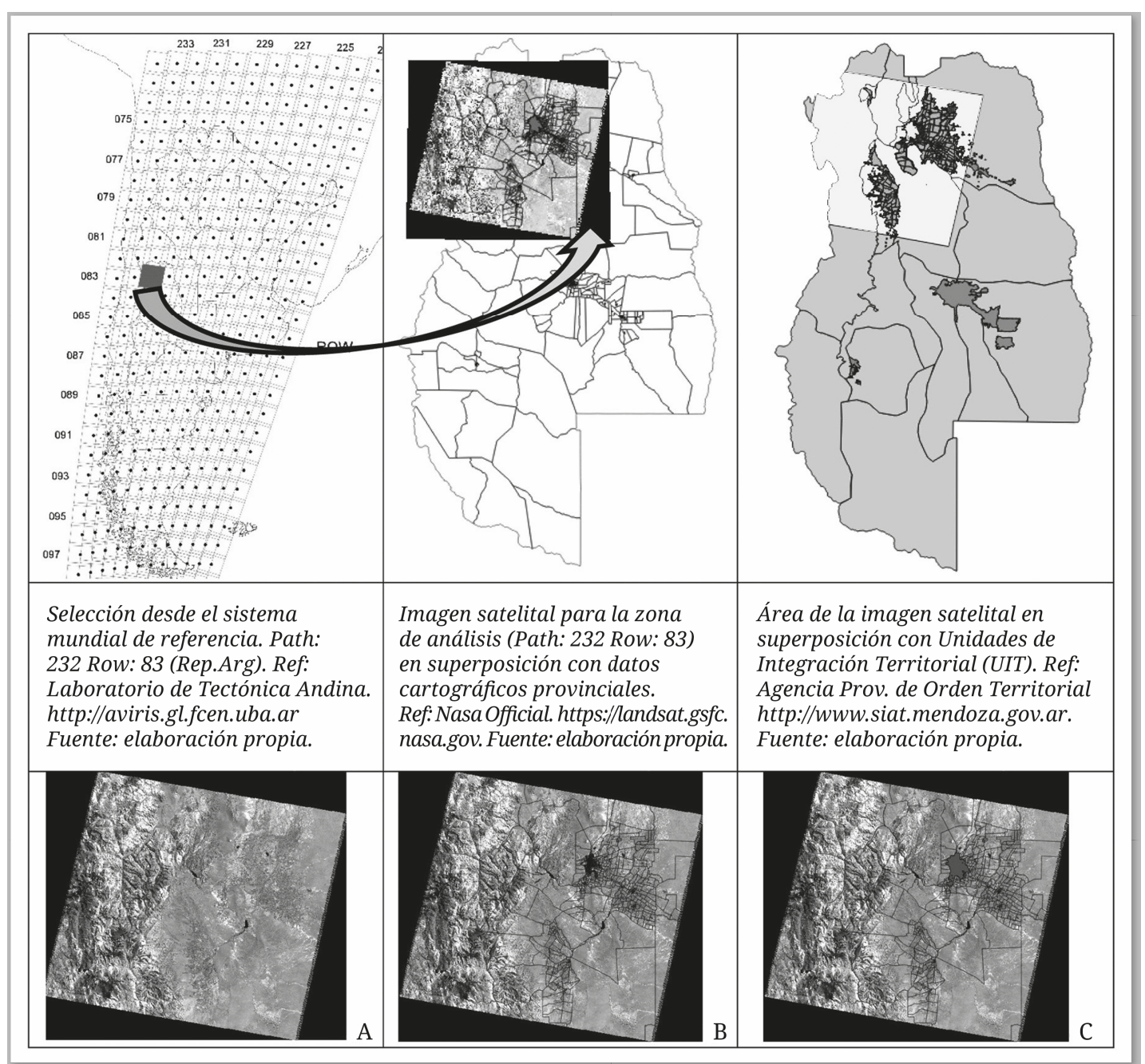

Figura 5. Pasos seguidos en la descarga de imágenes satelitales. A) Imagen satelital 27/02/2011; $B$ ) superposición con datos cartográficos secciones catastrales; $\mathcal{C}$ ) superposición con AMM y datos cartográficos secciones catastrales. Ref: IRONS, J. Nasa Official, 2016-2017; Datos cartográficos: Dirección Provincial de Catastro, 2012/2013 e INDEC, (2010). Fuente: elaboración propia. 
Preprocesamiento de imágenes satelitales: las imágenes satelitales, al ser obtenidas de sensores remotos, adquieren cierto tipo de interferencias. Para eliminar las perturbaciones se preprocesaron las imágenes efectuando correcciones geométricas, radiométricas y atmosféricas (MorAn ET ÁL. 1992, CHAVEz, 1996 y MASEK ET ÁL., 2006).

Determinación del Índice de Vegetación: el Índice de Vegetación de Diferencia Normalizada (NDVI) proporciona la fracción de la radiación fotosintéticamente activa interceptada por la vegetación (CHuvieco, 2002) y es útil para estimar la cantidad, calidad y desarrollo de la vegetación, la absorción de energía por la cobertura arbórea, el funcionamiento en el ecosistema (Rodríguez-Moreno, 2013), la identificación de ecorregiones y el seguimiento de patrones fenológicos con los cambios estacionales y de crecimiento. Se obtiene a partir de las bandas 4 y 3; permite determinar valores de reflectancia a distintas longitudes de onda (GILABERT ET ÁL., 1997), resulta del cociente normalizado entre bandas espectrales que al mostrar un claro contraste entre las bandas visibles $(0.6$ a $0.7 \mu \mathrm{m})$ y el infrarrojo cercano $(0.7$ a $1.1 \mu \mathrm{m}$ ) permiten identificar la vegetación de otras superficies (Chuvieco, 2000) mediante la siguiente ecuación:

$$
N D V I=(N I R-R) \cdot(N I R+R)_{(1)}
$$

Los resultados del NDVI varían entre -1 y +1; valores altos revelan actividad fotosintética de la cubierta vegetal (fenología foliar) y una estrecha relación con la evapotranspiración (TUCKER \& SELLERS, 1986); valores bajos indican situaciones de escasa o nula cubierta vegetal y baja actividad fotosintética; valores negativos corresponden principalmente a nubes, agua y nieve.

Posprocesamiento de imágenes satelitales: las imágenes Landsat cubren grandes áreas. Para facilitar los cálculos en la cartografía georreferenciada de secciones catastrales, fue necesario crear un archivo en formato GIS de las 32 manzanas en estudio, tomando como límite los ejes de calles a fin de considerar el arbolado y superficies verdes públicas y privadas (figuras 3 y 6). Se calcularon los valores medios NDVI para cada polígono correspondiente a las manzanas urbanas seleccionadas (figuras 3, 7 y 8). 
Estimación del índice de vegetación en entornos urbanos forestados consolidados de baja densidad del área Metropolitana de Mendoza, Argentina

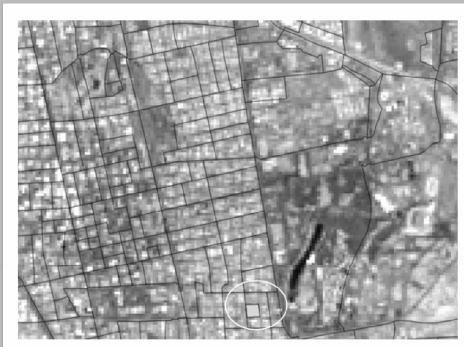

Figura 6. Resultado NDVI para la imagen satelital parcial 27/02/2011. Fuente: elaboración propia.

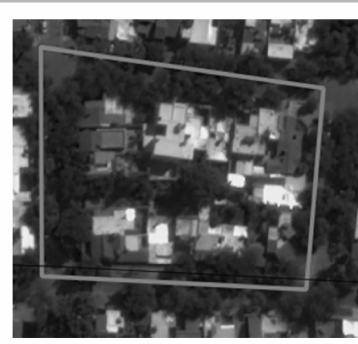

Figura 7. Imagen manzana de análisis. Fuente: elaboración propia.

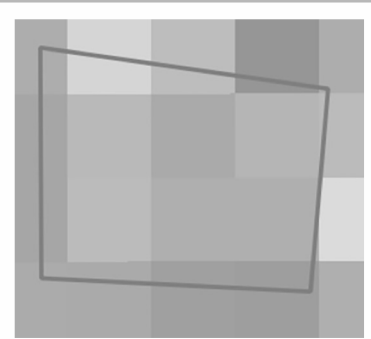

Figura 8. Resultado NDVI para la imagen satelital parcial de la manzana urbana 27/02/2011. Fuente: elaboración propia.

Se determinó la superficie de análisis del Área Metropolitana de Mendoza $\left(252 \mathrm{~km}^{2}\right)$ a partir de imágenes de contaminación lumínica nocturna (Earth Observation Group, 2016) considerando como límite una radiancia mayor a $20\left(10^{-9} \mathrm{~W} / \mathrm{cm}^{2} \cdot \mathrm{sr}\right)$, y se generó un archivo en formato GIS; se calcularon los valores NDVI del AMM y de las Unidades de Integración Territorial correspondientes a la imagen de análisis (figuras 1, 3 y 5). Se compararon los valores NDVI resultantes de los 32 casos de estudio con valores medios para el AMM y para las unidades de integración territorial.

\section{Resultados}

\section{Resultados de áreas verdes y superficies mineralizadas}

Del total de la superficie presente en los 32 entornos urbanos analizados, el $63.98 \%$ lo ocupan áreas privadas (dentro de la línea de edificación de las manzanas) y el $36.02 \%$ de áreas restantes son públicas (fuera línea de edificación). Los resultados obtenidos indican valores medios de área verde superficial del 20,22 \% (pública y privada) (figura 9) y del $22.83 \%$ si sumamos otras áreas permeables de terreno natural. En cuanto a las áreas verdes cuantificadas desde una vista aérea, el $26.59 \%$ está representado por las copas del arbolado (figura 10). 


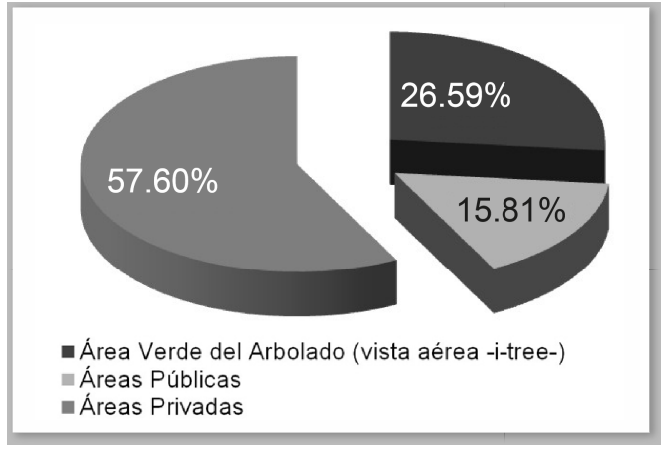

Figura 9. Área

verde superficial

pública y privada.

Fuente: elaboración

propia

Figura 10. Área verde arbolada desde una vista aérea. Fuente: elaboración propia

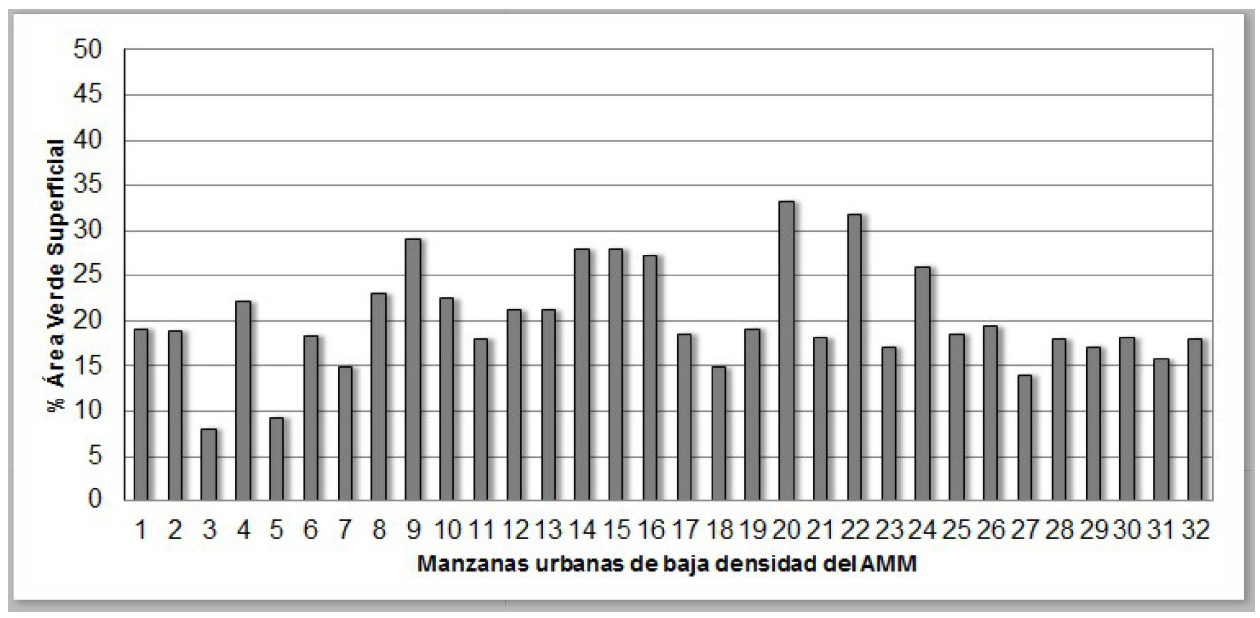

El área verde superficial en el interior de las manzanas urbanas representa un recurso importante, al igual que la arborización urbana de calles (figuras 10 y 11). Por lo tanto, la gestión pública y privada posee una responsabilidad compartida en el modelo urbano actual de ciudad. En zonas privadas la cubierta forestal es del 6.38 \%, un valor limitado respecto del arbolado público. La incorporación de arbolada en el interior de las manzanas debería ser considerada dentro de los planes y políticas de fomento de espacios verdes en la ciudad. 
Estimación del índice de vegetación en entornos urbanos forestados consolidados de baja densidad del área Metropolitana de Mendoza, Argentina

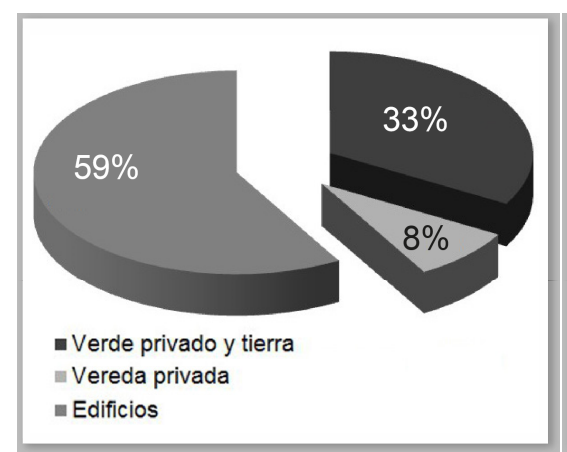

Figura 11. Áreas Privadas. Fuente: elaboración propia

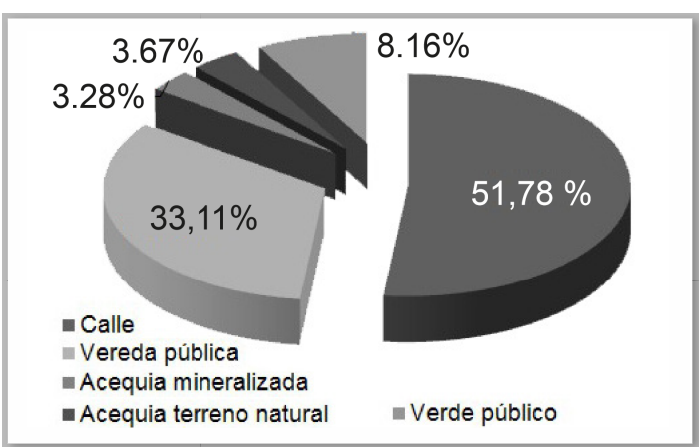

Figura 12. Áreas Públicas. Fuente: elaboración propia

El mayor porcentaje de cubierta forestal presente en las manzanas urbanas se ubica en áreas públicas (calles, veredas, acequias); las copas de los árboles cubren el $56.61 \%$; el valor máximo de follaje sobre áreas públicas de las manzanas analizadas fue del 87.5 \% (ARBOIT, BetMAN 2016). Si incorporamos además las áreas verdes superficiales públicas (jardines existentes en las veredas), el porcentaje de verde sobre superficies mineralizadas públicas es mayor. En el análisis de áreas públicas cubiertas por el arbolado coexisten situaciones diversas en la trama urbana, relacionadas con el desarrollo histórico de la ciudad: áreas metropolitanas con ejemplares de gran desarrollo y plenitud de implantación y áreas con la estructura arbórea más abierta y discontinua representada por ejemplares jóvenes, nuevas plantaciones de ejemplares, pérdida o reemplazo de arbolado, o especies dañadas, longevas y deterioradas.

Otro aspecto importante es el porcentaje destinado a circulación vehicular en relación con las áreas peatonales. En este sentido, el modelo de ciudad forestada presente en los 32 entornos de baja densidad del AMM posee los siguientes valores: el 51.78 \% de las áreas son circulación vehicular y el 48.22 \% restante área no vehicular (veredas, cordón, áreas verdes, acequias permeables e impermeables) (figura 12).

En la figura 13 se detalla la composición de veredas que representan el 18 \% de las áreas de los 32 entornos urbanos de baja densidad analizados. De un análisis bidimensional del 100 \% de la superficie de dichas veredas, el 68 \% está representado por el área de cordón 
de banquina-vereda y áreas peatonales (generalmente con sellamiento del suelo y cubiertas por materiales artificiales e impermeables o revestidas en baldosas calcáreas); el 15 \% está representado por acequias, de las cuales el $8 \%$ son abiertas y el $7 \%$, cubiertas.

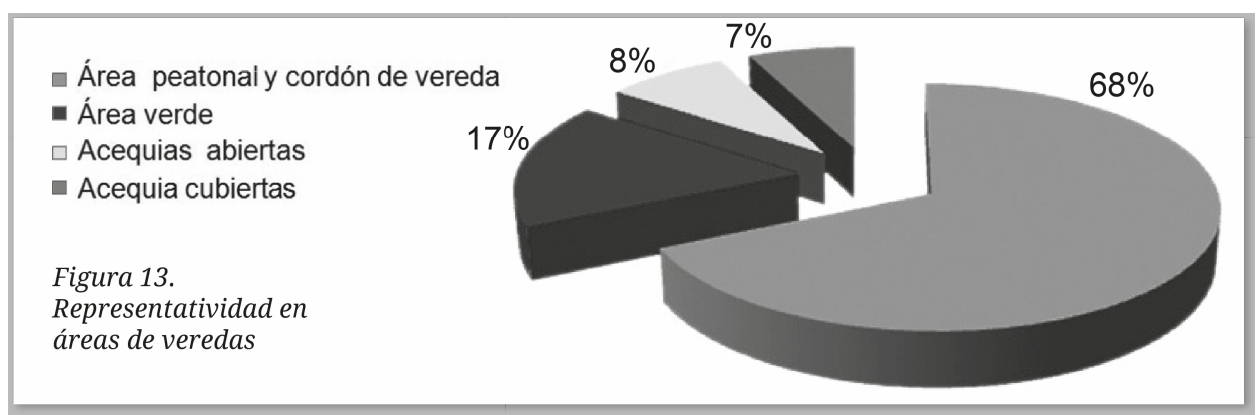

Las áreas verdes superficiales de tipo bidimensional (2 D) están presentes en el paisaje urbano especialmente en los entornos de baja densidad, y se les reconoce -más allá de los beneficios ligados al mejoramiento del microclima- el mérito principal de reducir la temperatura superficial, ya que absorben cerca del 80 \% de la energía incidente; parte de ella la utilizan para la evapotranspiración que permite mantener baja la temperatura superficial. El coeficiente de reflexión de un jardín o prado verde es cercano al 15-20 \%, que permite mantener baja la radiación reflejada hacia las superficies vecinas.

Si analizamos la morfología urbana de los 32 escenarios estudiados , la relación entre espacio abierto (público y privado) y el espacio construido (edificios), el espacio abierto ocupa el $39.66 \%$, mientras el espacio construido, el $60.34 \%$. Las superficies construidas al interno de las 32 manzanas urbanas estudiadas se incrementaron en los últimos diez años un 9.22 $\%$ con pérdida y disminución de superficie de patios y espacios verdes y aumento de la relación espacio-construido / espacio-abierto.

Persiste sin solución, en los espacios privados, el porcentaje de mineralización antrópica, con las tendencias siempre en crecimiento, sin contemplar la conservación de la cubierta arbórea, la forestación, el diseño de áreas verdes superficiales en dichas intervenciones. En este sentido, la legislación del verde es imperante hacia el futuro. 
Estimación del índice de vegetación en entornos urbanos forestados consolidados de baja densidad del área Metropolitana de Mendoza, Argentina

\section{Resultados NDVI para las manzanas urbanas}

En la figura 14 se presentan los resultados obtenidos del índice de vegetación de diferencia normalizada (NDVI) para los 32 entornos urbanos de baja densidad del AMM.

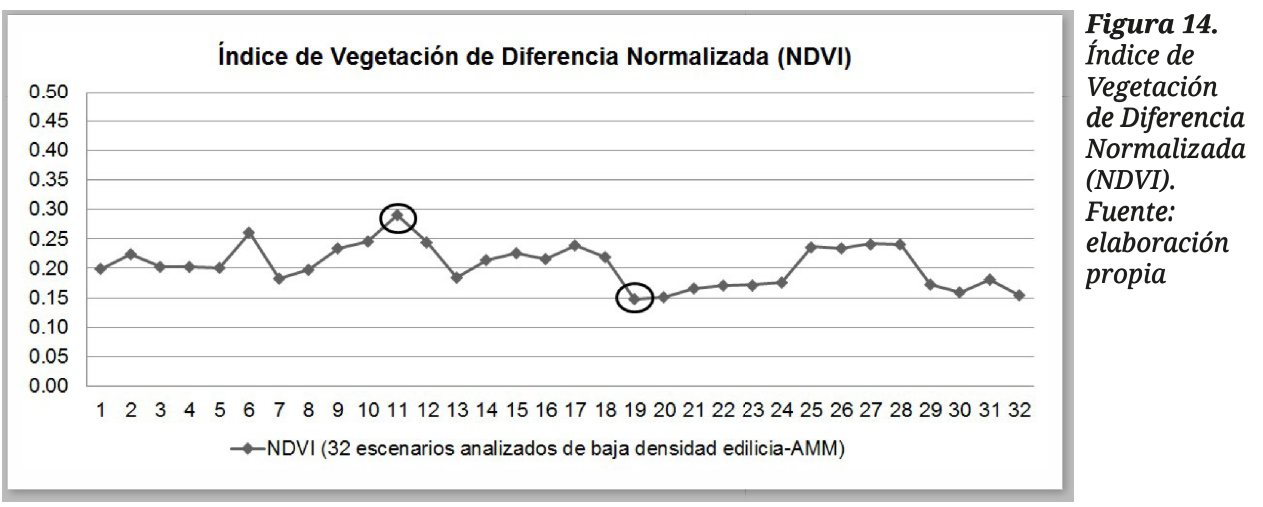

El valor medio para los 32 entornos analizados es de 0.206 , con el índice más alto de 0.290 representado por el escenario 11, que resulta ser el más favorable. Los valores mínimos se obtuvieron en el escenario 19, con un NDVI de 0.148.

Análisis escenario 11 y escenario 19: en el caso del escenario 11 (figuras 15-17), el espacio público posee una cubierta forestal caracterizada por la presencia de árboles de grandes dimensiones con su capacidad para disipar la radiación solar. La representatividad de las especies vegetales en dicha manzana es la siguiente: $49.9 \%$ morera (Morus alba), $42.68 \%$ fresno europeo (Fxaxinius excelsior), $2.439 \%$ acer (Acer negundo), $1.83 \%$ fresno americano (Fraxinus americana L.), $1.83 \%$ acacia visco y blanca (Robinia pseudoacacia), $0.61 \%$ paraíso común (Melia azedarach), $0.61 \%$ paraíso sombrilla (Melia azedarach fm. umbraculifera) y $0.61 \%$ de ciruelo rojo (Prunus cerasifera var. Pissardii).

Los valores inversos a la transmisividad solar en la estación de verano son representativos de las sombras arrojadas por el arbolado sobre superficies mineralizadas que en su mayoría están por sobre el $80 \%$ : morera 85.47\%, fresno $81.12 \%$, acer $85.96 \%$, paraíso $80.21 \%$ y paraíso sombrilla 98.39 \% (CANTón, 2000; Arboit, 2013; CARretero, 2017). 
El valor de plenitud del arbolado en el escenario N. ${ }^{\circ} 11$ es del $68 \%$. El impacto del enmascaramiento producido por el arbolado urbano, con sus características morfológicas y de transmisividad, en este caso compensa el porcentaje de ejemplares faltantes alrededor de la manzana respecto de la cantidad máxima posible, teniendo en cuenta la distancia adecuada de plantación entre individuos.

Los resultados obtenidos a nivel de superficie de suelo (relevamiento in situ y datos catastrales) considerando la totalidad de superficies (públicas y privadas) revelan que un alto porcentaje es mineralizada: $79.67 \%$, de los cuales el $20.13 \%$ son superficies de calzada (calle), el $14.54 \%$ veredas, $1.42 \%$ acequias impermeabilizadas, $3.77 \%$ de áreas privadas con sellamiento de suelo (terrazas, bordes perimetrales peatonales, accesos, etc.) y el 39.81 $\%$ construida (edilicia).

Para el mismo entorno el área verde superficial es del $20.34 \%$, la superficie parquizada privada representa el $15.07 \%$, la superficie parquizada pública, el 3.81\%, con un $1.46 \%$ de acequias permeables. En este caso, la densidad de la copa de árboles en verano permite un mayor enmascaramiento de la radiación solar incidente en dicho entorno y ayuda a compensar el sellamiento de suelo y la escasa disponibilidad de áreas verdes superficiales a nivel de suelo. Si bien algunas viviendas aún conservan el modelo tradicional de espacio verde público y privado en veredas y accesos frontales vegetados (figura 18), existe una tendencia cada vez más difundida de sellamiento de estos espacios y reemplazo por superficies mineralizadas.

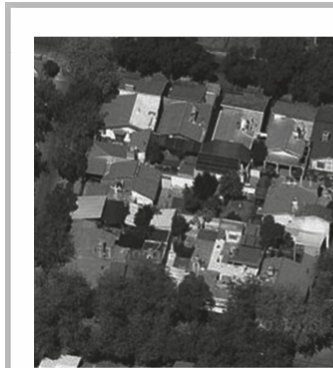

Figura 15. Escenario 11 Fuente: Google maps

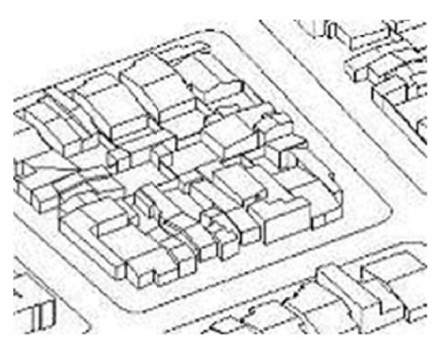

Figura 16. Volumetría edilicia. Fuente: elaboración propia

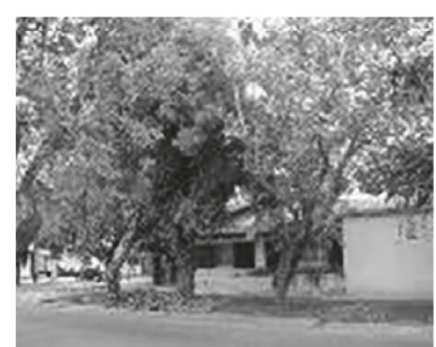

Figura 17. Trazado urbano. Fuente: elaboración propia 
Estimación del índice de vegetación en entornos urbanos forestados consolidados de baja densidad del área Metropolitana de Mendoza, Argentina

Volviendo al análisis de los valores mínimos de NDVI 0.148 obtenidos en el escenario 19, dicho entorno, aunque posee arbolado urbano, no alcanzaría a compensar las superficies construidas y selladas.

En cuanto a las características de las variables del arbolado urbano, posee una heterogeneidad de especies arbóreas en su mayoría de tercera magnitud, con un patrón de disposición espacial de ejemplares individuales y en condición de contiguos (ejemplares apareados), y la plenitud de implantación del $54 \%$, lo que indica una falta del $46 \%$ de ejemplares en la manzana urbana. Estos aspectos combinados con las intervenciones por poda deterioran aún más el estado del arbolado público existente.

En el escenario 19 la falta de ejemplares y el estado del arbolado público influyen decisivamente en el NDVI. Si analizamos los resultados obtenidos a nivel de superficie de suelo (relevamiento in situ y datos catastrales) el área verde superficial es del $29.99 \%$ (valores mayores al escenario 11), el $27.20 \%$ son áreas verdes privadas (patios parquizados); el 1.35 \%, áreas verdes públicas y el $1.44 \%$, acequias sin impermeabilizar (figura 18).

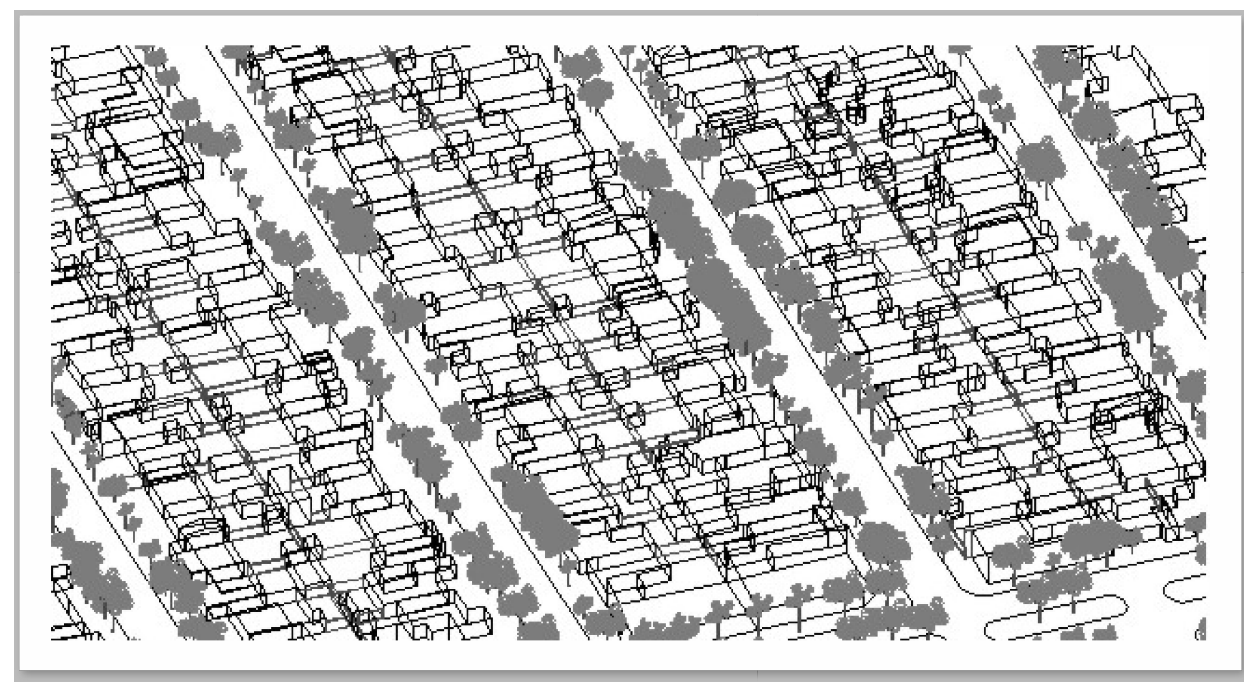

Figura 18.

Escenario 19.

Volumetría

ediliciay

arbolado

urbano. Fuente:

elaboración

propia 
Las superficies mineralizadas expuestas al sol directo representan el $70.01 \%$, de las cuales el $17.23 \%$ es superficie de calzada-calle; el $8.86 \%$, veredas; el $0.73 \%$, acequias impermeabilizadas; el $6.80 \%$, áreas privadas con sellamiento de suelo (terrazas, bordes perimetrales peatonales, accesos, etc.) y el $36.39 \%$, construida (edilicia).

Si comparamos los valores de NDVI del escenario 11 con el escenario 19 (figura 15), queda demostrado cómo una mejora en la cubierta forestal compensa significativamente las superficies mineralizadas y puede favorecer escenarios con mayor porcentaje de superficies mineralizadas y menor porcentaje de áreas verdes superficiales a nivel de suelo.

Resultados NDVI para el AMM: si analizamos para la totalidad del área Metropolitana de Mendoza (AMM), el valor medio de NDVI es de 0.249 .

El NDVI de los 32 escenarios analizados de baja densidad edilicia del AMM (0.206) está por debajo del valor medio del área urbana, ya que no se consideran espacios recreativos verdes públicos (plazas, parques y jardines) y dicho resultado se ubica muy por debajo de los oasis de cultivo.

Análisis comparativo de los resultados NDVI para las Unidades de Integración Territorial: la figura 19 permite la comparación del AMM (ubicada en el Oasis Norte y bajo procesos de irrigación) con las tierras irrigadas de cultivo ubicadas en el mismo oasis. El valor medio NDVI del Oasis Norte cultivado al oeste del río Mendoza es de 0.314; el del Oasis Norte cultivado al este del río Mendoza es de 0.350 y los valores medios del AMM son de 0.249.

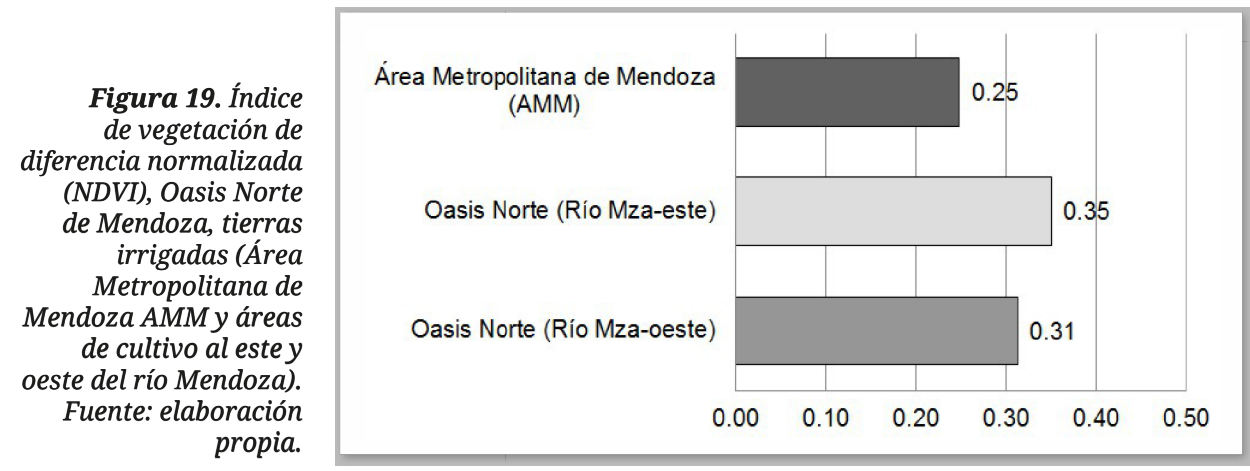


Estimación del índice de vegetación en entornos urbanos forestados consolidados de baja densidad del área Metropolitana de Mendoza, Argentina

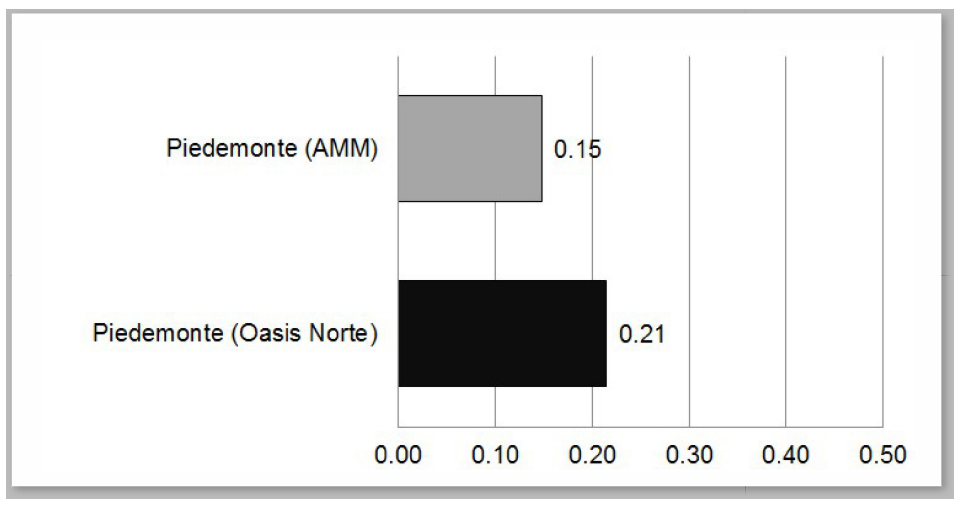

Figura 20. Índice de vegetación de diferencia normalizada (NDVI), Piedemonte no irrigado (Áreas de piedemonte influenciada por urbanizaciones recientes del AMMy áreas de piedemonte natural). Fuente: elaboración propia.

Si comparamos los valores del piedemonte alcanzados por el área urbana, el valor de NDVI es de 0.148 , mientras el piedemonte no intervenido por actividades antrópicas es de 0.214 . La expansión de la mancha urbana sobre el piedemonte hacia el oeste está comprometiendo seriamente las condiciones ambientales y favoreciendo riesgos aluvionales en las zonas adyacentes a la zona construida (figura 20).

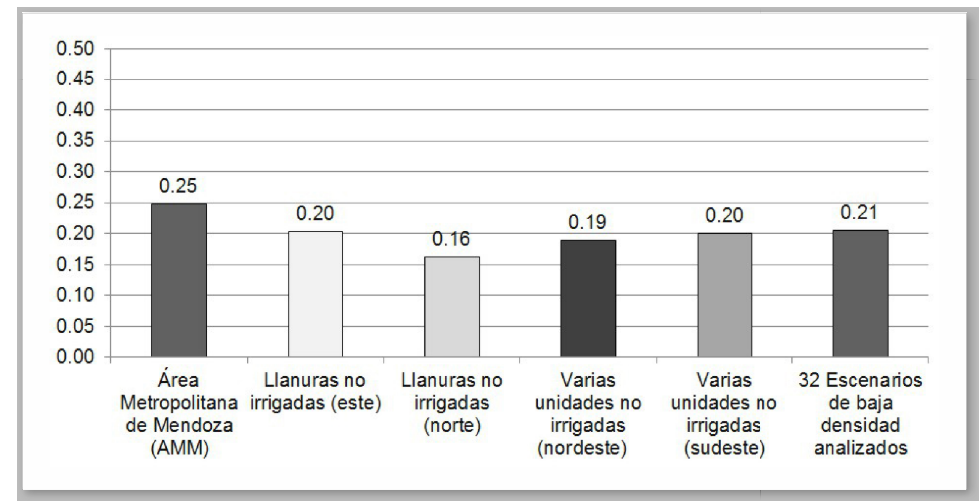

Figura 21.

Indice de

vegetación

de diferencia

normalizada

(NDVI). AMM,

tierras de secano

mendocino

(llanuras y

otras unidades

no irrigadas) y

escenarios de baja

densidad. Fuente:

elaboración

propia. 
Otro aspecto que considerar son las tierras de secano; los valores de las llanuras no irrigadas al norte cuyo NDVI es de 0.162 y las llanuras no irrigadas al este cuyo NDVI es de 0.204 (figura 21). Los valores alcanzados de los 32 entornos urbanos analizados se acercan significativamente a los de tierras no irrigadas cercanas al Área Metropolitana de Mendoza. Se estableció este resultado como estado base de la distribución de esta variable en relación con las tierras secas, que ha permitido principalmente la comparación del AMM (ubicada en el Oasis Norte y bajo procesos de irrigación) con las tierras no irrigadas del secano mendocino.

\section{Conclusiones}

Se formuló un diagnóstico de la cobertura vegetal sobre la base del índice de vegetación de diferencia normalizada (NDVI) adaptado a entornos consolidados de baja densidad en un modelo de ciudad forestada en clima árido. A escala urbana el NDVI se ve explicado en gran parte por la cubierta forestal y por las áreas verdes superficiales a nivel del suelo.

La correlación entre el arbolado y los valores de NDVI está a su vez íntimamente relacionada con las variables plenitud, transmisividad y la magnitud de los ejemplares presentes en las manzanas. Este estudio posibilitaría mejoras en el índice de vegetación, a partir del completamiento de ejemplares faltantes por manzana, con fuerte dependencia de las especies utilizadas. La gestión pública y el acompañamiento privado en la tutela de los forestales aparecen como las principales estrategias a corto plazo. Existe además una correlación entre la cobertura vegetal del suelo en prados y jardines especialmente aquella altamente irrigada y los valores NDVI, que determinan una mayor o menor actividad vegetativa. Modificaciones incrementales y progresivas de áreas verdes superficiales y cubiertas arbóreas en el ámbito privado podrían efectivamente implementarse para mejorar los niveles de sostenibilidad ambiental y energética del parque edilicio urbano en la región.

Los planificadores urbano-edilicios necesitan establecer proyectos prioritarios a nivel territorial y definir criterios de manejo y metas cuantitativas específicas, que incluyan el espacio privado. Los municipios enfrentan grandes retos en la legislación de indicadores verdes para los códigos de edificación urbana, esenciales para asegurar la continuidad y afianzar el modelo de ciudad forestada en climas secos. Otro desafío es concretar un modelo consensuado y sostenible a partir de la incorporación de especies de bajo consumo hídrico pero 
Estimación del índice de vegetación en entornos urbanos forestados consolidados de baja densidad del área Metropolitana de Mendoza, Argentina

con abundante masa verde, y resolver la modernización de la infraestructura de riego del arbolado público con diseño de sistemas más eficientes, acordes con el modelo de oasis y factibles de ser implementados en ciudades en vías de desarrollo.

En lo referente a la metodología utilizada, la comparación entre áreas verdes superficiales y superficies mineralizadas a nivel de suelo, el estudio de la cubierta forestal a partir de una vista aérea y los valores resultantes de las imágenes satelitales NDVI de las 32 manzanas urbanas, valores medios del AMM y las distintas Unidades de Integración Territorial (analizados en GIS) permitieron comprobar el impacto antrópico en entornos consolidados de baja densidad en un modelo de ciudad forestada, y evaluar diversas estructuras urbanas y territoriales. Se han logrado datos y documentos cartográficos de consulta. A nivel de la resolución espacial, fue necesario un extenso conocimiento del mundo real para la detección de los diversos tipos de estructuras urbanas existentes debajo de la copa de los árboles, como por ejemplo, la identificación de diversas superficies mineralizadas, que sin el relevamiento in situ o cambio de resolución de imágenes satelitales no sería posible cuantificar.

Se obtuvo, además, información base de procesos de desertificación para el área de trabajo. Se caracterizaron las tierras de secano mendocino dentro de la imagen satelital (llanuras y otras unidades no irrigadas), tierras irrigadas del oasis norte de Mendoza (AMM y áreas de cultivo al este y oeste del río Mendoza) y áreas de piedemonte no irrigado (influenciadas por urbanizaciones recientes del AMM y áreas de piedemonte natural). Esta caracterización a partir de valores medios de NDVI permitió detectar y comprender las variaciones de la radiación fotosintéticamente activa interceptada por la vegetación en la ciudad forestada y su comparación a nivel territorial donde coexisten heterogeneidades físico-estructurales en un complejo de interrelaciones entre microclima, uso del suelo, vegetación, recursos hídricos y otros.

La metodología para el diagnóstico de la cobertura vegetal sobre la base del índice de vegetación es factible de ser implementada en la totalidad de las manzanas urbanas del Área Metropolitana de Mendoza, a fin de conocer las condiciones actuales - pero también a partir de un estudio multitemporal de las imágenes disponibles desde los 80 a la actualidad-, comprender los cambios recientes en la vegetación, determinar los cambios vinculados con procesos de urbanización a nivel espacial y completar los estudios vinculados con la morfología urbano-edilicia para la sostenibilidad energético ambiental. 


\section{Bibliografía}

AGENCIA PROVINCIAL DE ORDENAMIENTO TERRITORIAL (2010-2017). "Sistema de Información Ambiental Territorial”. SIAT (APOT), LADyOT (CCT - CONICET), Instituto CIFOT (FFyL, UNCuyo). http://www.siat.mendoza.gov.ar.

AKBARI, H. (2002). "Shade trees reduce building energy use and CO2 emissions from power plants”. Environ. Pollut, 116.

AKBARI, H.; KONOPACKI, S. (2005). "Calculating energy-saving potentials of heat-island reduction strategies”. Energy Policy, 33.

ARBOIT, M. (2013). "Permeabilidad del arbolado urbano a la radiación solar: Estudio de dos especies representativas en entornos urbanos de baja densidad del Área Metropolitana de Mendoza, Argentina”. Revista Hábitat Sustentable. Vol. 3, N. ${ }^{\circ}$ 2, Chile.

ARBOIT, M.; DIBLASI, A.; FERNÁNDEZ LLANO, J. C. and DE ROSA, C. (2008). "Assessing the solar potential of low density urban environments in andean cities with desert climates - The case of the city of Mendoza, in Argentina”. Renewable Energy. Elsevier Editorial System. Vol. 33, tomo 8, Renewable Energy, Oxford UK.

ARBOIT, M.; MESA, A DIBLASI, A.; FERNÁNDEZ LLANO, J. C. y DE ROSA, C. (2010). “Assessing the solar potential of low density urban environments in andean cities with desert climates - The case of the city of Mendoza, in Argentina. 2nd. Part”. Renewable Energy. Elsevier Editorial System. Vol. 35, UK.

ARBOIT, M. and BETMAN, E. (2016). "Comparative Study of Solar Radiation Availability in Dry Climate Urban Environment Forested Areas in Mendoza Argentina”. International Journal of Civil and Environmental Engineering, Vol. 37, Londres.

ARMSON, D.; STRINGER, P.; ENNOS, A. R.(2012). "The effect of tree shade and grass on surface and globe temperatures in an urban area”. Urban Forest. Urban Greening, 11.

BERNATZKY, A. (1982). "The contribution of trees and green spaces to a town climate". Energy Build.

BLOCK, A. H.; LIVESLEY, S. J.; WILLIAMS, N. S. G. (2012). "Responding to the Urban Heat Island: A Review of the Potential of Green Infrastructure". Victorian Centre for Climate Change Adaptation Research Melbourne.

BREHENY, M. (1996). “Centrist, Decentrists and Compromisers inThe Compact City”. E \& FN Spon, London.

CANTÓN, M. A.; MESA, A.; CORTEGoso, J. L. and DE ROSA, C. (2003). "Assessing the solar resource in forested urban environments: results from the use of a photographic-computational method”. Architectural Science Review, 46, 2. 
Estimación del índice de vegetación en entornos urbanos forestados consolidados de baja densidad del área Metropolitana de Mendoza, Argentina

CARRETERO, E; MORENO, G.; DUPLANCIC, A; ABUD, A.; VENTO, B.; JAUREGUI, J. (2017). "Urban forest of Mendoza (Argentina): the role of Morus alba (Moraceae) in carbon storage”. Carbon Management.

CHAVEZ, P. S. (1996). "Image-based atmospheric corrections". Revisited and improved. Photogrammetric Engineering and Remote Sensing, 62.

CHUVIECO, E. (2000). "Fundamentos de teledetección espacial”. Rialp, Madrid.

CHUVIECO, E.; MARTIN, M. P.; PALACIOS, A. (2002). "Assessment of different spectral indices in the red-near-infrared spectral domain for burned land discrimination". International Journal of Remote Sensing 23 (23).

DE ROSA, C. (1988). "Conjunto Solar 1-bioclimatic and passive design applied to low-cost multistorey housing”. Proceedings of the 6th international PLEA conference. Porto, Portugal. DESSİ, V. (2002). "Comparison between thermal comfort simulation and user's behaviour in an open space.” AUAE (Architectural and Urban Ambient Environment), Nantes.

DIRECCIÓN PROVINCIAL DE CATASTRO (2012/2013). http://www.mendoza.gov.ar/.

EARTH OBSERVATION GROUP. NOAA National Geophysical Data Center. https://ngdc.noaa. gov/eog/night_sat/nightsat.html and www.lightpollutionmap.info.

ELLINGSWORTH, D.; BINKLEY, M. AND MACO, S. (2016). "I-Tree”. I-Tree Canopy Technical Notes. www.itreetools.org.

GILABERT, M.A., GONAZÁLES-PIQUERAS, J. and GARCÍA-HARO, J. (1997). “Acerca de los Índices de Vegetación”. Revista de Teledetección, N. ${ }^{\circ} 8$.

GIVONI, B. (1998). "Climate considerations in building and urban design”. John Wiley \& Sons, Inc., USA.

GÓMEZ-MUÑOZ, V. M.; PORTA-GÁNDARA, M. A.; FERNÁNDEZ, J. L. (2010). “Effect of tree shades in urban planning in hot-arid climatic regions”. Landsc. Urban Plann, 94.

HAIDER, Taha (1997). "Urban climates and heat islands: albedo, evapotranspiration, and anthropogenic heat”. Energy and Buildings, 25.

HAMADA, S.; OHTA, T. (2010). "Seasonal variations in the cooling effect of urban green areas on surrounding urban areas”. Urban Forest. Urban Greening, 9.

HARMAN, Ian Nicholas (2003). "The energy balance of urban areas”. The University of Reading. Department of Meteorology.

HEISLER (1986). "Effects of individual trees on the solar radiation climate of small buildings”. Urban Ecology, volume 9, Issues 3-4. Special Issue Ecology of the Urban Forest II.

HUETE, A. R.; LIU, H. Q. (1994). "An error and sensitivity analysis of the atmospheric- and soil-correcting variants of the NDVI for the MODIS-EOS”. IEEE Transactions on Geoscience and Remote Sensing, N. ${ }^{\circ} 32$. 
ICES (2013). “Indicadores de la Iniciativa Ciudades Emergentes y Sostenibles”. Banco Interamericano de Desarrollo.

INSTITUTO NACIONAL DE ESTADÍSTICA Y CENSOS DE LA REPÚBLICA ARGENTINA (2010). http://www.indec.gob.ar/.

IRONS, James R. (2017).NASA OFFICIAL.Landsat Science. Actualización julio 6, 2017. https://landsat.gsfc.nasa.gov/the-worldwide-reference-system/.

LABORATORIO DE TECTÓNICA ANDINA (2017). Departamento de Ciencias Geológicas Facultad de Ciencias Exactas y Naturales Universidad de Buenos Aires. http://aviris.gl.fcen. uba.ar/Curso_SR/biblio_sr/biblio_sr. htmly.

LENNEY, M. P.; C. E. WOODCOCK, J. B.; COLLINS \& HAMDI, H. (1996). "The status of agricultural lands in Egypt: The use of multitemporal NDVI features derived from landsat TM". Remote Sensing of Environment, 56.

LING TANG, L.; ZHANG, G. (2013). "The Pattern and Gradient Analysis of Urban Green Space in Shenyang, China”. Communications in Information Science and Management Engineering. Vol. 3 Iss. 2.

LOUGHNER, C. P. (2012). "Roles of urban tree canopy and buildings in urban heat island effects: parameterization and preliminary results”. J. Appl. Meteorol. Climatol, 51.

MASCARÓ, L. (1996). “Ambiencia urbana”. European Comisión, Directorate-General XVII, Energiy. Faculdade de Arquitetura UFRGS. Sagra D. C. Luzzato Editores, Porto Alegre.

MASEK, J. G., E. F. VERMOTE, N. SALEOUS, R. WOLFE, F. G. HALL, F. HUEMMRICH, F. GAO, J. KUTLER, and LIM, T. K. (2006). "A Landsat surface reflectance data set for North America” 1990 - 2000, Geosci. Remote Sens. Lett., 3.

MCPHERSON E. G.; SIMPSON J. R. and LIVINGSTON, M. (1989). "Effect of three landscape treatments on residential energy and water use in Tucson, AZ”. Energy Build, 13.

MCPHERSON, E. G. 1992. “Accounting for benefits and cost of urban greenspace”. Landscape and Urban Planning.

MCPHERSON, E. G.; J. R. SIMPSON (1998). "Simulation of tree shade impacts on residential energy use for space conditioning in Sacramento". Atmospheric Environmental: Urban Atmospheres. 32, 1.

MEADOWS, D. H.; MEADOWS, D. L.; RANDERS, J. (1992). "Beyond the limits”. Earthscan Publications Limited. London.

MONTEITH, J. L. (1973) Principles of Environmental Physics. Edward Arnold, Londres.

MONTEITH, J. L. and UNSWORTH, M. H. (1990) Principles of Environmental Physics. 2da. ed. Edward Arnold, Londres. 
Estimación del índice de vegetación en entornos urbanos forestados consolidados de baja densidad del área Metropolitana de Mendoza, Argentina

MORAN, M. S.; JACKSON, R. D.; SLATER, P. N. and TEILLET, P. M. (1992). "Evaluation of simplied procedures for retrieval of land surface reflectance factors from satellite sensor output”. Remote Sensing of Environment, 41.

NOWAK, D. J.; STEVENS, J. C.; SISINNI, S. M. and LULEY, C. J.(2002). "Effects of urban tree management and species selection on atmospheric carbon dioxide". Journal of Arboriculture, 28, 3.

OKE, T. R. (1988). “The urban energy balance”. Prog. Phys. Geogr. 12.

OKE, T. R. and EAST, C. (1971). "The urban boundary layer in Montreal, Bound". Layer Meteorol, 1.

OKE, T. R.; JOHNSON, G. T.; STEYN, D. G. and WATSON, I. D. (1991). "Simulation of surface urban heat islands under 'ideal' conditions at night”. Part 2: Diagnosis of causation, Bound. Layer Meteorol, 56.

OWENS, S. (1986). "Energy planning and urban form”. London: Pion Ltd.

PAPADAKIS, G.; TSAMIS, P. \& KYRITSIS, S. (2001). "An experimental investigation of the effect of shading with plants for solar control of buildings". Energy and Buildings, 33.

PARKER, J. H. (1983). "The effectiveness of vegetation on residential cooling”. Passive Solar a. 2. RAMSEY, R. D.; A. FALCONER and R. JENSEN. (1995). "The relationship between NOAAAVHRR NDVI and Ecoregions in Utah”. Remote Sensing of Environment, 53.

RODRÍGUEZ-MORENO, V. M. and BULLOCK, S. H. (2013). "Comparación espacial y temporal de índices de la vegetación para verdor y humedad y aplicación para estimar LAI en el desierto Sonorense”. Revista Mexicana de Ciencias Agrícolas. 4 (4).

ROTH, M. (2013). "Urban Heat Islands". Handbook of Environmental Fluid Dynamics, Volume Two, edited by Harindra Joseph Shermal Fernando.

ROWNTREE, R. A. (1986). "Ecology of the urban forest - Introduction to Part II". Urban. Ecology, 9.

SANTAMOURIS, M. (2000). "Energy and Climate in the Urban Built Environment”. James and Jamnes, London.

SCUDO, G.; OCHOA DE LA TORRE, J. M. (2003). "Spazi verdi urbani, la vegetazione come strumento di progetto per il comfort ambientale negli spazi abitati”. Esselibri, Napoli.

SHASHUA-BAR and HOFFMAN, M. E. (2000). "Vegetation as a climatic component in the design of an urban street”. An empirical model for predicting the cooling effect of urban green areas with trees. Energy and Buildings, 31.

SHASHUA-BAR L.; ERELL E.; PEARLMUTTER D. (2009). "The cooling efficiency of urban 
landscape strategies in a hot dry climate”. Landscape and Urban Planning, 92.

SHASHUA-BAR; PEARLMUTTER D. and ERELL, E. (2011). "The influence of trees and grass on outdoor thermal comfort in a hot-arid environment”. International journal of climatology, 31 .

SIMPSON, J. R. (2002). "Improved estimates of tree-shade effects on residential energyuse". Energy Build, 34.

TOOKE, T. R.; COOPS, N. C.; VOOGT, J. A.; MEITNER, M. J. (2011). "Tree structure influences on roof top-received solar radiation”. Landsc. Urban Plann. 102.

TUCKER, C. J. and SELLERS, P. J. (1986). "Satellite remote sensing of primary production". Int J Remote Sensing, 7.

VIRGINIA, R. A.; WALL, D. H. (2001). "Principles of Ecosystem function". Levin, SA (ed.) Encyclopedia of Biodiversity. Academic Press, San Diego, USA. 